\title{
Autopoiesis, Observation and Informatics: Lessons from the Development of Autopoietic Systems Theory in Japan
}

\author{
Wataru Hashimoto
}

wat.hashimoto@gmail.com, Graduate School of Interdisciplinary Information Studies, University of Tokyo, Japan

\begin{abstract}
This article is concerned with redefining the notion of information from a perspective of systems theory. In recent years, the notion of information, which was closely related to the framework of old cybernetics, has been refined in parallel with the emergence of new cybernetics, especially second-order cybernetics and autopoiesis. The systemic view of new cybernetics provides us with the notion of "informationally closed system." This notion is congruent with the epistemological implications of radical constructivism. In order to help understand this argument, we aim at highlighting the development of autopoietic systems theory in Japan. Autopoiesis has often been considered as a thoroughly closed system in Japan, where the relationships between autopoiesis and radical constructivism have frequently been overlooked. This is mainly because the importance which autopoietic systems theory originally attaches to the notion of observer and observation has been inadequately discussed, and autopoietic systems theory is regarded as distinct from second-order cybernetics and radical constructivism. However, they must be dealt with together, and Humberto Maturana should be given credit for his ontology of observing. Since the publication of his paper "Biology of Cognition," Maturana has been attempting to explain the notion of observation as a biological phenomenon in his own way. Likewise, by taking into consideration the notion of observation, we can build a unified theory of information. Fundamental Informatics, which is being developed by Toru Nishigaki, outlines a unified approach to information by putting human observers at the center of his theory. Social and mechanical information is generated only when human observers conduct observations on the basis of biological information, and this mechanism of generation of information is discussed through the notion of "hierarchical autonomous system." For an autopoietic organization to be realized, of course, no hierarchy of systems is required, but observers are likely to construct some hierarchy between two systems. The construction of certain hierarchies of systems by observers is of great use for the explanation of fictitious phenomena of information transmission.
\end{abstract}

Keywords: autopoiesis, observation, radical constructivism, Fundamental Informatics, hierarchical autonomous system

The aim of this article is to conduct an investigation of the concept of information from the perspective of systems theory, and in particular of second-order cybernetics and autopoietic systems theory. In this article, we are concerned especially with the development of autopoietic systems theory in Japan. In recent years, some Japanese systems theorists have been studying intensively about the relationships between autopoiesis and observation. Their discussion provides us with an important clue to understanding how systems theory should contribute to the advancement of informatics.

We adopt second-order cybernetics and autopoietic systems theory as a central theory for the following two reasons.

First, these systems theories provide us with new notions of cognition. The importance of the cognitive view has recently been recognized in information studies, such as information retrieval research. Now that we have realized that the relationships between cognition and information must not be ignored, the shift in the view of cognition should also lead to that of information. Therefore, if systems theories today are revolutionizing the notion of cognition, then the concept of information should go through changes at the same time.

Second, the scientific conception of information, in origin, is closely related to cybernetics. In Cybernetics (1948) and the Human Use of Human Beings (1954), Norbert Wiener, the founder of cybernetics, identified information with negative entropy, and stated that "the information carried by a set of messages is a measure of organization" (Wiener, 1954, p. 21). About a quarter of a century after Wiener's invention of cybernetics, Heinz von Foerster began to advocate second-order cybernetics, and Humberto Maturana and Francisco Varela coined the term "autopoiesis". The new trend 
in cybernetics, including second-order cybernetics and autopoiesis, Gordon Pask (1992) calls "new cybernetics". Between old and new cybernetics, even the same set of terminology differs greatly in signification. Table 1 shows some of the differences.

\begin{tabular}{|l|l|}
\hline \multicolumn{1}{|c|}{ OLD } & \multicolumn{1}{c|}{ NEW } \\
\hline $\begin{array}{l}\text { INFORMATION } \\
\text { Selective or Statisti- } \\
\text { cal }\end{array}$ & $\begin{array}{l}\text { Coupling of organi- } \\
\text { zationally closed } \\
\text { distinct systems }\end{array}$ \\
\hline $\begin{array}{l}\text { DISTINCTION } \\
\text { By external observer, } \\
\text { may be on good } \\
\text { common-sense } \\
\text { grounds }\end{array}$ & $\begin{array}{l}\text { By closure, of sys- } \\
\text { tems. Is, for exam- } \\
\text { ple, complementary } \\
\text { to productive proc- } \\
\text { ess. May be supple- } \\
\text { mented by observer }\end{array}$ \\
\hline $\begin{array}{l}\text { OBSERVATION } \\
\text { Essentially External, } \\
\text { Impartial, value free }\end{array}$ & $\begin{array}{l}\text { Essentially Partici- } \\
\text { pant, entails value }\end{array}$ \\
\hline $\begin{array}{l}\text { EPISTEMOLOGY } \\
\text { Varied, but knowl- } \\
\text { edge is usually seen } \\
\text { as there, in data, } \\
\text { fats, rules, and so on }\end{array}$ & $\begin{array}{l}\text { Unless qualified, is } \\
\text { act of coming to } \\
\text { know, personal or } \\
\text { shared and public } \\
\text { concepts }\end{array}$ \\
\hline
\end{tabular}

Table 1: Conceptual differences between old and new cybernetics (Pask, 1992, pp. 24-25, extracted)

Needless to say, information is one of the central concepts in cybernetics, and the new trend in cybernetics provides us with a novel view of information.

In the next section, we will make a brief comparison between the view of information in old cybernetics and that in new cybernetics.

\section{Several Views of Information}

In recent years, the concept of information has been elaborated on the basis of systems theory, particularly autopoietic systems theory (Aguado, 2009; Brier, 1992, 2008; Hashimoto, 2008; Mingers, 1999; Qvortrup, 1993; Pervez, 2009). These studies agree on criticism of the mechanistic view of information.

Qvortrup (1993) classifies the existing concept of information into four types:

1. something identifiable in the real world, i.e. a difference in reality

2. a difference which makes a difference, i.e. a difference in reality which causes a mental difference

3. a difference which finds a difference, i.e. a conceptual difference which finds or which is confirmed (or triggered) by something in the outer world.

4. a cognitive difference which brings forth (an idea about) an external world. (Qvortrup, 1993, pp. 3-4)

The first type of definition means that information is something existing in the external world. This position considers information to exist as an ontological entity independent of its observer. Aguado (2009) calls this position the "positivist" one. By contrast, the fourth type of definition views information as something only in the human mind. As long as these two types are discussed, con- 
troversies over the concept of information will surely come back to the traditional subject-object problem. In order to make a breakthrough, we have to examine the second and the third types of concept of information.

Aguado (2009) calls the second type "the constructivist position", and the third type "the radical constructivist position." The constructivist position regards information as something coherent with an idea of communication, which can be understood as a coupling between two interacting systems. Indeed, this conception of information parallels Gregory Bateson's definition of information, "a difference which makes a difference." On the other hand, the radical constructivist position is based mainly on the epistemological implications of distinguished systems theorists, Heinz von Foerster, Ernst von Glasersfeld, Humberto Maturana and Francisco Varela. We will provide a brief overview of each position.

\subsection{Batesonian View of Information}

In order to appreciate Bateson's definition "a difference which makes a difference," it is important to position information as a key concept in the epistemology he was building. For him, "the mental world - the mind - the world of information processing —is not limited by the skin" (Bateson, 1972, p. 460). He aims to expand mind outside the body and saw the whole ecosystem as the mind. The following quotation shows his epistemology clearly.

The cybernetic epistemology which I have offered you would suggest a new approach. The individual mind is immanent but not only in the body. It is immanent also in pathways and messages outside the body; and there is a larger Mind of which the individual mind is only a subsystem. This larger Mind is comparable to God ... but it is still immanent in the total interconnected social system and planetary ecology (Bateson, 1972, p. 467).

Bateson sees the whole ecology as an informational circuit and the transform of a difference traveling in the circuit as an elementary idea (ibid, p. 460). In addition, he refers to his own epistemology as both "holistic" (Bateson, 1979, p. 87) and "monistic" (Bateson, 1991, p. 217). The idea that he had come up with when he was preparing for the Korzybski Lecture is stated as follows:

It is only news of difference that can get from the territory to the map, and this fact is the basic epistemological statement about the relationship between all reality out there and all perception in here: that the bridge must always be in the form of difference. Difference, out there, precipitates coded or corresponding difference in the aggregate of differentiation which we call the organism's mind (Bateson, 1991, p. 218).

Let us summarize the main points of Bateson's ecological epistemology and information.

1. The ecological system is a recursive circuit in which differences travel and undergo transformation.

2. Information cannot be localized in itself. Information is necessarily relative to the boundary of a subsystem, and can be presumed outside the subsystem.

3. His epistemology is compatible with the theory of logical types. In other words, it is hierarchical.

4. His epistemology is concerned with the entire system, and is characterized as monism.

\subsection{Radical Constructivist View of Information}

In brief, radical constructivism investigates autonomous systems as "informationally-closed systems." To borrow von Glasersfeld's phrase, in informationally-closed systems, cognition "serves the subject's organization of the experiential world, not the discovery of an objective ontological reality" (Glasersfeld, 1995, p. 51). Reality is invented recursively as a result of the self-reference of the system, and information is constructed inside the system. To put it another way, "the environment contains no information" (Foerster, 1970/2003, p. 189). 
There is a sharp contrast between the radical constructivist view of information and the Batesonian one. In the latter, information is supposed to move beyond system boundaries. In contrast, radical constructivists consider information as something formed inside a system.

We miss the point if we regard radical constructivism merely as rehashing traditional solipsism. Von Glasersfeld (1985) points out the novelty of radical constructivism as follows:

A genuinely constructivist theory of knowledge must deal not only with the process of cognitive construction but also with the relationship which the results of any such construction might have to the reality of the traditionally presumed ontological world. That relationship, I believe, is the very point in which radical constructivism is revolutionary (Glasersfeld, 1985/2007, p. 22).

Von Glasersfeld does not concede that radical constructivism will lead to the philosophical position in which "anything goes." No cognition is arbitrary. He insists that cognition functions as long as it is viable, as can be seen in the following quotation:

We construct ideas, hypotheses, theories, and models, and as long as they survive, which is to say, as long as our experience can be successfully fitted into them, they are viable (Glasersfeld, 1981/1987, p. 138).

Maturana shares a similar perspective on cognition with von Glasersfeld. In interpreting Maturana, indeed, von Glasersfeld (1990) clearly states that "according to Maturana, cognizing organism is informationally closed." In "Biology of Cognition," Maturana explains the notion of information as follows:

The notion of information refers to the observer's degree of uncertainty in his behavior within a domain of alternatives defined by him, hence the notion of information only applies within his cognitive domain. Accordingly, what one could at most say is that the genetic and nervous systems generate information through their self-specification when witnessed by the observer as if in their progressive self-decoding into growth and behavior (Maturana, 1970/1980, pp. 54-55).

This quotation suggests that the use of the term "information" requires the observer to observe the system and its environment.

In Maturana's terminology, informational closure can be further explained by the introduction of "structure determinism." This concept means that all changes in a structure-determined system are necessarily determined by its structure. Therefore, any change triggered through the interactions of a structure-determined system is determined by its structure. And the same situation is true of the medium (environment), which is also seen as a structure-determined system. Thus, the structure of the system changes together with that of the medium. This dynamics of structural changes that take place in the interactions between the system and the medium is called "structural coupling."

The notion of structural coupling is a radical constructivist alternative to Bateson's view of information. Radical constructivist position puts an emphasis on the structure determinism and the structural coupling at the same time. The epistemological significance of the radical constructivist position lies in system closure rather than system openness.

\section{Diversity of Orientations to Autopoiesis}

In this section, to help understand how the notion of autopoiesis should be evaluated, we will take a look at the situation in which Maturana and Varela's autopoietic systems theory has been received in Japan. In Japan, Hideo Kawamoto, a philosopher of science, translated Maturana and Varela's Autopoiesis and Cognition into Japanese, and has been contributing to development of autopoetic systems theory in his own original way.

Kawamoto (1995) classifies typical systems theories into three generations, and refers to autopoiesis as the third-generation system. The first-generation system is a system in dynamic equilibrium, which is modeled after metabolism and, therefore, is characterized as an open system. 
Homeostasis, introduced by Walter Cannon, belongs to this generation. The second-generation system is a self-organizing system, a typical of which can be found in crystal deposition in a beaker. While the first-generation views the hierarchical relationship as stable, the secondgeneration is concerned with the realization of the hierarchy itself. Despite this noteworthy difference in approaches to hierarchy, both the first-generation and the second-generation systems are characterized by system openness. In addition, it is an observer that sets the boundary between a self-organizing system and its environment.

The third-generation system, that is, autopoiesis can be distinguished from both the firstgeneration and the second-generation system in terms of hierarchical relationship and the position of observers in theorization.

From the original definition of autopoiesis that Maturana and Varela (1973/1980, pp. 78-79) give, two notable features of an autopoietic system are obtained. First, autopoietic systems are autonomous, and furthermore, they have no inputs or outputs. Secondly, atutopoietic systems' boundaries are not drawn by an observer, but rather "their operations specify their own boundaries in the process of self-production" (Ibid, p. 81). For an autopoietic organization to be realized, therefore, neither hierarchical relationships nor an observer is required, or rather is relevant at all.

According to Kawamoto (1995), autopoiesis can be put at the latest generation. This contrasts markedly with Hayles' explanation of the history of cybernetics. Hayles (1999) divides the development of cybernetics into three waves. The first wave, from 1945 to 1960, regarded homeostasis as central. This is nearly identical to what Kawamoto calls the first-generation system. The second wave, roughly from 1960 to 1980 , developed the concept of reflexivity and put an emphasis on cybernetics of observing systems, that is, second-order cybernetics. Heinz von Foerster, Humberto Maturana and Francisco Varela belong to the second wave. The invention of autopoiesis by Maturana and Varela constituted the mature point of the second wave. According to Hayles, the third wave from 1980 to the present has developed on the basis of virtuality. Central to the third wave is the development of artificial life and cellular automata.

Although this chronological explanation of cybernetics is easy to understand, her assessment of the second wave is absolutely irrelevant. Clarke and Hansen (2009) criticize her discussion as an attempt to delineate a "third-wave" cybernetics. On the contrary, Clarke and Hansen put an emphasis on the novelty and effectiveness of "neocybernetics". The term "neocybernetics" is intended to suggest that second-order cybernetics and autopoiesis are not to be surmounted. In this respect, Kawamoto shares his view of autopoiesis with Clarke and Hansen, and we can assess Kawamoto's explanation as valid.

It is necessary, however, to explain the difference between Kawamoto and Maturana with regard to the notion of atupoiesis. Kawamoto $(2000,2002,2006)$ reformulates the concept of autopoiesis in his own original way. His redefinition of autopoiesis is aimed at expanding "kôi-sonzairon" (actontology). Kôi-sonzairon suggests that as long as the operation of an autopoietic system is maintained, its boundary is self-determined, and the system (or an entity) is realized and comes into being. Kawamoto sets koi-sonzairon apart from another type of ontology, that is, "ninshikisonzairon" (recognition-ontology). Ninshiki-sonzairon means that existence or objects are constructed by the act of observation.

Note that Kawamoto's approach is quite different from Maturana's one. Maturana's conception of observation and Spencer-Brown's calculus of indication are parallel. In his work Laws of From, Spencer-Brown (1969) formulates the calculus of indication, whose implication is that "a universe comes into being when a space is severed or taken apart" (Spencer-Brown, 1969, p. v). For Spencer-Brown, drawing a distinction allows an entity to exist. Likewise, Maturana proposes the constitutive ontology of observers. Maturana defines the notion of observer as follows:

An observer is a human being, a person, a living system who can make distinction and specify that which he or she distinguishes as a unity, as an entity different from himself or herself that can be used for manipulations or descriptions in interactions with other observers. An observer can make distinctions in actions and thoughts, recursively.... Everything said is said by an observer to another observer, who can be himself or herself (Maturana, 1978, p. 31). 
The question now is the way that the realization of an autopoietic organization and the act of observing are to be related to each other. Let us consider the following two quotations on cognitive systems and the cognitive domain.

A cognitive system is a system whose organization defines a domain of interactions in which it can act with relevance to the maintenance of itself, and the process of cognition is the actual (inductive) acting or behaving in this domain. Living systems are cognitive systems, and living as a process is a process of cognition (Maturana, 1970/1980, p. 13).

"The cognitive domain is the entire domain of interactions of the organism. The cognitive domain can be enlarged if new modes of interactions are generated. Instruments enlarge our cognitive domain (Ibid, p. 38).

These quotations succinctly show Maturana's conception of biology of cognition. For Maturana, cognition co-occurs with the living, that is, the realization of an autopoietic organization. And the enlargement of domains of interactions leads to that of the cognitive domain. Furthermore, we as a species can co-ordinate consensual co-ordinations of actions. These second-order co-ordinations of actions Maturana calls "languaging."

There are circumstances in which an observer can see that under the expansion of a consensual domain of co-ordinations of actions there is a recursion in the co-ordinations of actions of the organisms that participate in it. ... I claim that when this occurs, language happens, and that the phenomenon of language takes place in the flow of consensual co-ordinations of consensual co-ordinations of actions between organisms that live together in a co-ontogenic structural drift. Furthermore, I also claim that with languaging observing and the observer arise ... (Maturana, 1987, pp. 46-47).

This quotation clearly shows that observation takes place in languaging. What is important is that for Maturana, the fundamental question is "no longer 'what is the essence of that which I observe?' but rather "how do I do what I do as an observer in observing?" (Maturana, 2002, p. 6). In his biology of cognition, Maturana as a biologist tries to explain how an observer operates as a biological phenomenon.

From what has been discussed above, the question about autopoiesis arises: How do we apply the concept of an observer to autopoietic systems theory? Then we have to choose between the following two options:

1. To apply the notion of autopoiesis strictly to the operation of systems. We should adhere to the definition of autopoiesis, and eliminate the concept of observer from theorization.

2. To combine the two concepts, autopoiesis and observation. We should aim at the ontology of observing, as Maturana does.

Kawamoto has chosen the first option; while Maturana has developed his own theory, taking into account both autopoiesis and observation. It may be even more appropriate to say that for Maturana the notion of autopoiesis is essential for the explanation of observing as a biological phenomenon. It is reasonable to suppose that while taking account of a totally new type of autonomous system, he still works on second-order cybernetics, that is, observation of observing systems.

In the following section, let us adopt Maturana's view of autopoiesis and observation, because the concept of observation is the key to laying out a vision for the advancement of informatics. Like Maturana, Fundamental Informatics has chosen the second option, by regarding the phenomenon of observing as a biological one.

\section{Fundamental informatics}

In recent years, as mentioned in Section 1, several studies applying autopoiesis to the notion of information have been made. Likewise, Toru Nishigaki (2004), a Japanese informatician, has developed Fundamental Informatics (FI) on the basis of autopoietic systems theory, including Niklas Luhmann's theory of autopoietic social systems. FI covers biological, psychic, and social phenom- 
ena of information, and is characterized by its unified approach to information. In FI, the concept of information is classified into biological (life) information, social information and mechanical information, and the relationships among the three types of information are examined. The key to establishing these relationships is the concept of observer and observing. In this respect, $\mathrm{Fl}$ is featured as a novel autopoietic systems theory merging with radical constructivism ${ }^{1}$.

Now let us highlight the novelty and validity of FI, by comparing FI with another consideration of information on the basis of autopoietic systems theory. As well as FI, Pervez (2009) sees information as constructed by an observer. Pervez rightly stresses the self-reference of distinctions and indications by an observer, and defines information as form. No doubt, this study can be called a radical constructivist approach. However, how an observer learns to observe is open to question. In short, autopoietic systems theory is not necessarily required in order to elaborate the notion of information as form. On the other hand, $\mathrm{FI}$ takes into consideration what Maturana really means by the notion of observer as a biological phenomenon.

Nishigaki (2004) gives his book a subtitle, Seimei kara Shakai e (from Life to Society). This subtitle is aimed at emphasizing the notion that observing, and what is more, social phenomena by observers are inseparable from biological phenomena. FI is not a theory just providing a typology of information. Instead, it provides a unified perspective on information, explaining the generation of several levels of information.

In FI, the biological level of information, namely biological (life) information, is defined as "a pattern by which a living thing generates patterns" (Nishigaki, 2004, p. 27). The generation of patterns by a living organism is self-referential process, and cannot be determined by any perturbation in the medium (environment). Therefore, processes of biological information production are compatible with Maturana's structure determinism. Needless to say, any living organism can generate patterns by its own information, and consequently, the notion of information is not confined to human beings. When Nishigaki (2005; Nishigaki and Takenouchi, 2009) refers to his own theorization as the "informatic turn," he expects the informatic turn to take the place of the linguistic turn. This reveals his understanding of life in general.

Nishigaki's biological view of information, which is distinct from Shannon-Weaver model of communication, leads to his comment on the impossibility of information transmission. A similar criticism is found in Maturana and Varela (1987). In pointing out the errors in the metaphor of the tube for communication, they state as follows:

Our discussion has led us to conclude that, biologically, there is no "transmitted information" in communication. Communication takes place each time there is behavioral coordination in a realm of structural coupling. ...The phenomenon of communication depends on not what is transmitted, but on what happens to the person who receives it (Maturana and Varela, 1987/1992, p. 196).

This consideration on the impossibility of information transmission drives us to the question of how social information is generated. In FI, social information can be generated only by an observer through his description. As stated above, $\mathrm{Fl}$ introduces the notion of observer as a key concept. In $\mathrm{FI}$, an observer is necessarily a human being. This idea is also compatible with Maturana's notion of observer.

As long as the autopoietic organization is maintained, a human being can be considered as a biological system, and at the same time also as a psychic (mental) system. According to Luhmann (1995), social and psychic systems are structurally coupled mutually. Without psychic systems involved, communication is impossible. This coupling is considered as a kind of interpenetration, because there is no causal relationship between social and psychic systems. Likewise, the coupling between a biological system and a psychic one can be called another kind of interpenetration. Needless to say, the moment the operation of a biological system comes to a halt, the psychic sys-

\footnotetext{
${ }^{1}$ Nishigaki (2009) also embraces von Glasersfeld's radical constructivism.
} 
tem also stops its operation. In other words, the conservation of autopoietic organization is requisite for a psychic system, and what is more, for an observer.

In the interpenetration process of a biological and a psychic system, the information generated through the operation of the biological system is used as the raw material for the psychic system's observation. With that, for observers, biological information is situated as "raw-information" (protoinformation), which leads the interpenetrated psychic system to the acts of observation and description. This process constitutes the generation of social information.

As noted above, $\mathrm{FI}$ denies the possibility of information transmission given by Shannon-Weaver model. Rather, information transmission in FI is considered a "fictitious phenomenon," which is made possible through the realization of "a hierarchical autonomous system." If both of the following requirements are met, we hold that a hierarchical autonomous system is in existence.

(1) The observer observes system A, making sure that it is autonomous and making a note to that effect. Then he/she changes the perspective, observes system B, making sure that it is autonomous and making a note to that effect. Then, he/she goes back to system A, repeating the same procedure, and then goes back to system $B$ again, and so on. As a result of this repetitive observation and description, the two systems are found to continue performing their operations stably, and to continue preserving their autonomy.

(2) While system $A$ is observed, it is found that in system A's operation system B is performing certain functions as an allopoietic system. And the observer can recognize that the operation of system $B$ is restricted by system $A$ as a result of the structural coupling between the two systems. However, while observing system $B$, the observer cannot recognize any restriction on system B's operation being imposed by system A (Nishigaki, 2007, pp. 20-21).

Note that hierarchical autonomous systems are characterized not by containment relationships, but by restricting or binding relationships in the operation of the systems. It may be felt somewhat strange that $\mathrm{FI}$ insists on hierarchies of systems, because autopoetic systems theory has rejected the belief in hierarchy. Nevertheless if we observe a system from an observer's perspective, the coupling between systems can be seen as hierarchical. What is important here is that an observer is necessarily a human being, and that systems' hierarchies are constructed by an observer. Since the organization of system B is evidently autopoietic, we do not imply that the entity of system $B$ is produced through the organization of system $A$, when we speak of hierarchical autonomous systems.

For a hierarchical autonomous system to be realized, an observer has to observe a higher-level system A. When we take a psychic system for a lower-level system, for example, a social system constitutes the higher-level system, which is perceived by an observer. While many studies, including social constructionism, have focused on the constructedness of the social world (e.g. Berger and Luckmann, 1967), radical constructivists are also interested in the issue of the construction of society. Von Glasersfeld (2008), after pointing out the notion of viability and communication, states as follows:

It is irrelevant whether or not you believe that society exists in its own right, knowledge of society can be gathered only from your own experience (Glasersfeld, 2008, p. 63).

The problem we have to ask here is whether the hierarchy constructed by an observer is arbitrary or not. The answer is that it is not. We observers have to construct certain hierarchies of systems according to the criteria of viability. In addition, to borrow von Foerster's phrase on reality, "having re-established reality, it may be interesting to note that reality appears a consistent reference frame for at least two observers" (Foerster, 1960/2003, p. 4). Likewise, the notion of society is constructed via the community of observers, and the society thus constructed is a consistent reference frame for the observers. To be short, we can indicate the above by the equation "reality = community" (Foerster, 1973/2003, p. 227).

Let us now return to the subject of information transmission. In Fl, information transmission is a fictitious phenomenon made possible by hierarchical autonomous systems. Even though two per- 
sons appear to transmit information to each other through media (language, TV, Internet, etc.), actually they do not. Each observer generates social information from raw-information formed through the autonomous operation of the biological system. Additionally, this process of generation of information is made possible only when communication continues on the social level.

\section{Conclusion}

To discuss $\mathrm{Fl}$ as a whole is beyond the scope of this brief article. We have omitted its extended discussion related to mechanical information because of space limit. However, what has been discussed in this article is expected to show that $\mathrm{Fl}$ is an alternative view of information to the Batesonian view. FI is based both on autopoietic systems theory and on systems hierarchy constructed by observers. In this respect, FI lies midway between the constructivist position and the radical constructivist one, and its unified approach provides us with a totally new monistic notion of information.

The Batesonian view of information is monistic, in that it is based on the ecosystem as a total system. On the other hand, radical constructivists put an emphasis on cognitive systems as informationally closed. This distinction between system openness and system closure is what FI should overcome. It is sure that insistence only on system closure might lead us back to the traditional dualism. The ontology of observing as a biological phenomenon opens up an interesting possibility of overcoming this dualism. Intervention by observers enables us to investigate distinct levels of information. Therefore, the notion of observer and observation is essential for the unified theory of information.

\section{References}

Aguado, J. M. (2009). Information, Self-Reference and Observation Theory in the Context of Social Sciences Epistemology. tripleC, 7(1), pp. 344-356.

Bateson, G. (1972). Steps to an Ecology of Mind. New York: Ballantine Books.

Bateson, G. (1979). Mind and Nature: A Necessary Unity. New York: Dutton.

Bateson, G. (1991). Sacred Unity: Further Steps to an Ecology of Mind. New York: Cornelia \& Michael Bessie Book.

Berger, P. L. and Luckmann, T. (1967). The Social Construction of Reality: A Treatise in the Sociology of Knowledge. New York: Doubleday.

Brier, S. (1992). Information and Consciousness: A Critique of the Mechanistic Foundation for the Concept of Information. Cybernetics and Human Knowing, 1(2-3), pp. 71-94.

Brier, S. (2008). Cybersemiotics: Why Information Is not Enough! Toronto: University of Toronto Press.

Clarke, B. and Hansen, M. B. N. (2009). Neocybernetic Emergence: Retuning the Posthuman. Cybernetics and Human Knowing, 16(1-2), pp. 83-99.

Foerster, H. von. (1960). On Self-Organizing Systems and their Environments. In Yovits, M. C. and Cameron, S. (Eds.), Self-Organizing Systems. New York: Pergamon Press. (Rpt, in Foerster, H. von. Understanding Understanding: Essays on Cybernetics and Cognition. New York: Springer-Verlag, 2003.)

Foerster, H. von. (1970). Thoughts and Notes on Cognition. In Garvin, P. (Ed.), Cognition: A Multiple View. New York: Spartan Books. (Rpt, in Foerster, H. von. Understanding Understanding: Essays on Cybernetics and Cognition. New York: Springer-Verlag, 2003.)

Foerster, H. von. (1973). On Constructing a Reality. In Preiser, F. E. (Ed.), Environmental Design Research. vol. 2, Stroudburg: Dowden, Hutchinson \& Ross. (Rpt, in Foerster, H. von. Understanding Understanding: Essays on Cybernetics and Cognition. New York: Springer-Verlag, 2003.)

Glasersfeld, E. von. (1981). The Concepts of Adaptation and Viability in a Radical Constructivist Theory of Knowledge. In Sigel, I., Golinkoff, R. and Brodzinsky, D. (Eds.), New Directions in Piagetian Theory and Their Application to Education. Hillsdale: Erlbaum. (Rpt. in The Construction of Knowledge: Contributions to Conceptual Semantics. Salinas: Intersystems Publications. 1987.)

Glasersfeld, E. von. (1985). Reconstructing the Concept of Knowledge. Archives de Psychologie, 53, pp. 91-101. (Rpt. in Larochelle, M. (Ed.), Key Works in Radical Constructivism. Rotterdam: Sense Publishers, 2008)

Glasersfeld, E. von. (1990). Distinguishing the Observer: An Attempt at Interpreting Maturana. Retrieved from http://www.univie.ac.at/constructivism/EvG/papers/125.2.pdf

Glasersfeld, E. von. (1995). Radical Constructivism: A Way of Knowing and Learning. London: Falmer Press.

Glasersfeld, E. von. (2008). Who Conceives of Society? Constructivist Foundations, 3(2), pp. 59-64.

CC: Creative Commons License, 2011. 
Hashimoto, W. (2008). Shisutemu-ron ni okeru "Jôhô-teki Heisa-kei" Gainen: Bateson/Maturana no Ninshikiron-teki Idô to Radhikaru-kôsei-syugi no itiduke wo megutte (The Concept of "Informationally Closed System" in Systems Theory: On the Epistemological Difference between G. Bateson and H. Maturana and the Postion of Radical Constructivism). Jôhô-gaku Kenkyû (Journal of Information Studies), no. 75, pp. 69-81.

Hayles, K. (1999). How We Became Posthuman: Virtual Bodies in Cybernetics, Literature, and Informatics. Chicago: University of Chicago Press.

Kawamoto, H. (1995). Ôtopoiêshisu: Daisan-sedai Shisutemu (Autopoiesis: The Third Generation Systems). Tokyo: Seidosha.

Kawamoto, H. (2000). Ôtopoiêshisu no Kakutyô (The Expansion of Autopoiesis). Tokyo: Seidosha.

Kawamoto, H. (2002). Metamorufôze: Ôtopoiêshisu no Kakushin (Metamorphose: The Core of Autopoiesis). Tokyo: Seidosha.

Kawamoto, H. (2006). Shisutemu Genshôgaku: Ôtopoiêshisu no Daiyon Ryôiki (System-Phenomenology: The Fourth Stage of Autopoiesis). Tokyo: Shinyôsha.

Luhmann, N. (1995). Social Systems. Stanford: Stanford University Press.

Maturana, H. (1970). Biology of Cognition. BCL Report, no. 9.0. University of Illinois. (Rpt. in Maturana, H. and Varela, F. Autopoiesis and Cognition: The Realization of the Living. Dordrecht: D. Reidel Publishing Co. 1980.)

Maturana, H. (1978). Biology of Language: The Epistemology of Reality. In Miller, G. A. and Lenneberg, E. (Eds.), Psychology and Biology of Language and Thought: Essays in Honor of Eric Lenneberg. New York: Academic Press.

Maturana, H. (1987). Reality: The Search for Objectivity or the Quest for a Compelling Argument. Irish Journal of Psychology, 9(1), pp. 25-82.

Maturana, H. (2002). Autopoiesis, Structural Coupling and Cognition: A History of These and Other Notions in the Biology of Cognition. Cybernetics and Human Knowing, 9(3-4), pp. 5-34.

Maturana, H. and Varela, F. (1973). Autopoiesis: The Organization of the Living. (Rpt. in Maturana, H. and Varela, F. Autopoiesis and Cognition: The Realization of the Living. Dordrecht: D. Reidel Publishing Co, 1980.)

Maturana, H. and Varela, F. (1992). The Tree of Knowledge: The Biological Roots of Human Understanding. Rev. ed. Boston: Shambhala.

Mingers, J. (1999). Information, Meaning and Communication: An Autopoietic Approach to Linking the Social and Individual. Cybernetics and Human Knowing, 6(4), pp. 25-42.

Nishigaki, T. (2004). Kisô Jôhô-gaku: Seimei kara Shakai e (Fundamental Informatics: From Life to Society). Tokyo: NTT Publishing.

Nishigaki, T. (2005). Jôhô-gaku teki Tenkai (The Informatic Turn). Tokyo: Shunjûsha.

Nishigaki, T. (2007). For the Establishment of Fundamental Informatics on the Basis of Autopoiesis: Consideration on the Concept of Hierarchical Autonomous Systems. Retrieved from http://www.digital-narcis.org/english/FI-English-01.pdf

Nishigaki, T. (2009). Zoku Kiso Jôhô-gaku: "Seimei teki Sosihki" no tameni (Fundamental Informatics II: for Vital Organization). Tokyo: NTT Publishing.

Nishigaki, T. and Takenouchi. T. (2009). The Informatic Turn - Who Observes the "Infosphere"? Journal of SocioInformatics, 2(1), pp. 81-90.

Pask, G. (1992). Introduction: Different Kind of Cybernetics. In Van de Vijver, G. (Ed), New Perspectives on Cybernetics: Self-Organization, Autonomy and Connectionism. Dordrecht: Kluwer Academic Publishers.

Pervez, A. (2009). Information as Form. tripleC, 7(1), pp. 1-11.

Qvortrup, L. (1993). The Controversy over the Concept of Information: An Overview and a Selected and Annotated Bibliography. Cybernetics and Human Knowing, 1(4), pp. 3-24.

Spencer-Brown, G. (1969). Laws of Form. London: Allen \& Unwin.

Wiener, N. (1948). Cybernetics: or Control and Communication in the Animal and the Machine. New York: Wiley.

Wiener, N. (1954). The Human Use of Human Beings. New York: Doubleday.

\section{About the Author}

Wataru Hashimoto

is a doctoral student at the Graduate School of Interdisciplinary Information Studies, the University of Tokyo. He holds a master's degree in Interdisciplinary Information Studies from the University of Tokyo. His research focuses on the epistemology of cybernetics, communication studies and informatics. He published the Japanese edition of Ernst von Glasersfeld's Radical Constructivism: A Way of Knowing and Learning from NTT Publishing Co., Ltd. in February 2010. 